\title{
Overexpression of neuritin in gastric cancer
}

\author{
MING YUAN ${ }^{1,2}$, YONGJUN LI ${ }^{1,2}, \mathrm{CHEN}_{2} \mathrm{ZHONG}^{2}$, YONGKANG LI ${ }^{2}$, JIANHUA NIU ${ }^{2}$ and JIANPING GONG ${ }^{1}$ \\ ${ }^{1}$ Department of General Surgery, Tongji Hospital at Huazhong Institute of Science and Technology, Wuhan, Hubei 430030; \\ ${ }^{2}$ Department of Hepatobiliary Surgery, The First Affiliated Hospital of Shihezi University, Shihezi, Xinjiang 832006, P.R. China
}

Received October 31, 2014; Accepted August 17, 2015

DOI: $10.3892 / \mathrm{ol} .2015 .3793$

\begin{abstract}
The aim of the present study was to investigate the expression of neuritin in gastric cancer tissues, in order to explore the association between the expression of neuritin and the occurrence and development of gastric cancer. Tissue specimens were collected from 58 patients with gastric cancer. Immunohistochemistry, western blot analysis and reverse transcription-polymerase chain reaction (RT-PCR) were used to determine the expression of neuritin in the gastric cancer and corresponding adjacent normal gastric tissues. The expression rate of neuritin in gastric cancer tissues was $96.55 \%(56 / 58)$, demonstrating no statistically significant difference from the expression rate in the adjacent normal tissues $(94.83 \%)$ $(\mathrm{P}>0.05)$. However, the rate of strong neuritin expression in gastric cancer tissues $(82.76 \%)$ was significantly increased compared with the rate in the adjacent normal tissues $(15.52 \%)$ $(\mathrm{P}<0.05)$. Neuritin expression exhibited no correlation with the gender or age of patients, tumor-node-metastasis staging, tumor depth, presence of lymph node metastasis, histological or pathological type of the tumor or presence of distant metastasis $(\mathrm{P}>0.05)$. As determined by RT-PCR and western blot analysis, the mRNA expression of neuritin in gastric cancer tissues was markedly increased compared with the expression in the adjacent normal tissues. In conclusion, neuritin is highly expressed in gastric cancer tissues, suggesting that neuritin may act as a novel potential target for the treatment of gastric cancer.
\end{abstract}

\section{Introduction}

Neuritin, also termed CPG15, is one of the candidate plasticity-associated genes that were first screened and identified from the rat hippocampus cDNA library by Nedivi et al in 1993 (1). This gene was found to promote the growth of neural processes, thus it was termed neuritin (1). Subsequent functional studies have verified the effects of neuritin on the

Correspondence to: Dr Jianping Gong, Department of General Surgery, Tongji Hospital at Huazhong Institute of Science and Technology, 1095 Jiefang Road, Wuhan, Hubei 430030, P.R. China E-mail: jianpinggongen@126.com

Key words: neuritin, gastric cancer, correlation, treatment growth of neural processes (2-4). In previous years, numerous studies have also revealed that, in addition to the nervous system, neuritin is also expressed in the liver, heart, lungs, skeletal muscle and other normal organs (5-7). Neuritin is also highly expressed in certain tumor tissues, including Kaposi's sarcoma (5-9), which indicates that neuritin may be associated with the growth and development of a variety of tissues and cells, and even involved in the pathogenesis of tumors.

Gastric cancer demonstrates the highest incidence of all cancers worldwide, with $\sim 900,000$ novel patients and $\sim 700,000$ associated mortalities each year (10). In 2005, the incidence of gastric cancer in China was 37.1 cases per 100,000 males and 17.4 cases per 100,000 females (10). China is a region with a high incidence of gastric cancer, but the early detection rate for gastric cancer is only 5\% in China (10). The majority of patients admitted to hospital are in the advanced stage of gastric cancer and less than one-half of these patients survive for $>5$ years (11). Therefore, the identification of a more effective method for detecting early-stage gastric cancer is urgently required for the diagnosis and treatment of gastric cancer. To the best of our knowledge, the expression of neuritin in gastric cancer has not been reported at present. The current study was conducted to investigate the expression of neuritin in gastric cancer tissues using immunohistochemistry, western blotting and reverse transcription-polymerase chain reaction (RT-PCR).

\section{Materials and methods}

Tissue specimens. Formalin-fixed, paraffin-embedded human specimens and fresh frozen tissues were obtained from the Department of Pathology at the First Affiliated Hospital of Shihezi University (Shihezi, Xinjiang, China). Gastric cancer and adjacent normal tissue specimens were obtained from patients with gastric cancer that had undergone curative surgery for gastric cancer at the First Affiliated Hospital of Shihezi University between 2010 and 2013. The total 58 patients consisted of 40 males and 18 females, with a median age at the time of surgery of 60 years (range, 35-80 years). No patients had received chemotherapy or radiotherapy prior to surgery. The diagnosis of all patients was histopathologically confirmed as gastric cancer, consisting of 4 cases of protruding type (6.70\%), 45 cases of ulcer type $(77.59 \%)$ and 9 cases of invasive type (15.52\%). The present study was conducted with approval from the Ethics Committee of Tongji Hospital (Wuhan, Hubei, China). Written informed consent was obtained from all participants. 
Immunohistochemistry. Formalin-fixed paraffin-embedded sections of the tumor tissues and each adjacent normal tissue were sliced to a thickness of $4 \mu \mathrm{m}$ and placed on slides coated with poly-L-Lysine (Shenzhen Boshida Optical Instrument Co., Ltd., Shenzhen, China). Subsequent to routine deparaffinization in xylene and rehydration, tissue sections were microwaved in $10 \mathrm{mM}$ citrate buffer $(\mathrm{pH} 6.0$; Sigma-Aldrich, St. Louis, MO, USA) at $95^{\circ} \mathrm{C}$ for $15 \mathrm{~min}$ for antigen retrieval, and the sections were naturally cooled at room temperature for $30 \mathrm{~min}$. The endogenous peroxidase activity was then blocked by incubation with $3 \%$ hydrogen peroxidase (Sigma-Aldrich) for $10 \mathrm{~min}$. Immunohistochemical staining for neuritin was performed using the Envision kit (ZSGB-Bio, Beijing, China). Briefly, the sections were incubated at $4^{\circ} \mathrm{C}$ overnight with primary antibody (rabbit anti-human neuritin polyclonal antibody; catalog no. PRS4101; dilution 1:200; Sigma-Aldrich) followed by washing with phosphate-buffered saline (PBS; Sigma-Aldrich) three times, for 5 min each time. The sections were incubated with the secondary antibody (biotinylated goat anti-rabbit IgG; catalog no. mx20311; dilution 1:500; Fuzhou Maixin Biotechnology Development Co., Ltd., Fuzhou, China) at $37^{\circ} \mathrm{C}$ for $30 \mathrm{~min}$, followed by washing with PBS three times, 5 min each time. Finally, color development was performed using the chromogen 3,3'-diaminobenzidine and $1 \%$ hydrogen, and the nuclei were counterstained with hematoxylin. PBS was used as a substitute for the primary antibody in the negative control.

The AB product scoring method was used to determine the presence of neuritin. The staining and the strength of staining of the cells were scored as A, as follows: 0 , no staining; 1 , cells were stained to light yellow; 2, cells were stained to brown or dark yellow; and 3, cells were stained to tan. The proportion of the stained cells in the sections was scored as B, as follows: 1 , $<10 \%$ of cells stained; $2, \geq 10 \%$ and $<50 \%$ of cells stained; 3 , $\geq 50 \%$ and $<75 \%$ of cells stained; and $4, \geq 75 \%$ of cells stained. The score for each sample was the product of A and B. Tissues with scores $\leq 4$ were considered to not express neuritin, tissues scoring 5-8 were considered to express neuritin and tissues scoring 9-12 were considered to strongly express neuritin.

Total RNA extraction and RT-PCR. Total RNA extraction from gastric cancer tissues and adjacent normal tissues was performed using a miRNeasy Mini Kit, according to the manufacturer's instruction (Qiagen, Inc., Valencia, CA, USA). RNA was then utilized as a template for cDNA synthesis using a Omniscript RT Kit (Qiagen, Inc.) and subsequently subjected to PCR reactions. The PCR conditions were as follows: 1 cycle of $5 \mathrm{~min}$ at $94^{\circ} \mathrm{C} ; 30$ cycles of $30 \mathrm{sec}$ at $94^{\circ} \mathrm{C}$, $30 \mathrm{sec}$ at $58^{\circ} \mathrm{C}$ and $60 \mathrm{sec}$ at $72^{\circ} \mathrm{C}$; and 1 cycle of $5 \mathrm{~min}$ at $72^{\circ} \mathrm{C}$. The PCR products were analyzed using $1.0 \%$ agarose gel electrophoresis and imaged by a gel documentation system (GelDoc XR; BioRad Laboratories, Inc., Hercules, CA, USA). The primers for neuritin were as follows: Upstream, 5'-CCG GAATTCCAATGGGACTTAAGTTGAACGGCAGATAT-3'; and downstream, 5'-CGCGGATCCGAAGGAAAGCCAGGT CGCTAAAGCT-3'.

The primers for the internal reference gene GAPDH were as follows: Upstream, 5'-GACCCCTTCATTGACCTCAA-3'; and downstream, 5'-TGCTTCACCACCTTCTTGAT-3'. The PCR amplification conditions for GAPDH, performed for 30 cycles, were as follows: $95^{\circ} \mathrm{C}$ for $5 \mathrm{~min} ; 95^{\circ} \mathrm{C}$ for $30 \mathrm{sec} ; 55^{\circ} \mathrm{C}$ for $45 \mathrm{sec}$; $72^{\circ} \mathrm{C}$ for $2 \mathrm{~min} ; 72^{\circ} \mathrm{C}$ for $10 \mathrm{~min}$; and $16^{\circ} \mathrm{C}$ for $1 \mathrm{~min}$.

Western blot analysis. Gastric cancer tissues and adjacent normal tissues were homogenized in lysis buffer and then transferred into Eppendorf PCR tubes (Eppendorf, Hamburg, Germany). Subsequent to agitation at $4^{\circ} \mathrm{C}$ and $50 \mathrm{rpm}$ for $1 \mathrm{~h}$, the homogenates were centrifuged at $4^{\circ} \mathrm{C}$ and $12,000 \mathrm{rpm}$ for $30 \mathrm{~min}$ prior to the supernatants being collected. The protein concentrations were quantified through spectrophotometric measurement (NanoDrop; Agilent Technologies, Santa Clara, CA, USA) and adjusted to the same level. The proteins were then separated by SDS-PAGE gel electrophoresis and transferred to polyvinylidene difluoride membranes (EMD Millipore, Inc., Billerica, MA, USA). Subsequent to blocking with $5 \%(\mathrm{w} / \mathrm{v})$ milk in PBS with $0.05 \%$ Tween 20 (PBS-T) for $4 \mathrm{~h}$ at room temperature, the membranes were incubated overnight at $4^{\circ} \mathrm{C}$ with primary antibody (rabbit anti-human neuritin polyclonal antibody; catalog no. PRS4101; dilution 1:200; Sigma-Aldrich) and monoclonal anti- $\beta$-actin antibody (dilution 1:2,500; Sigma-Aldrich), respectively. The membranes were then incubated with secondary antibody (horseradish peroxidase conjugated polyclonal goat anti-rabbit IgG; catalog no. mx5546; dilution, 1:100; Fuzhou Maixin Biotechnology Development Co., Ltd., Fuzhou, China) for $2 \mathrm{~h}$ at room temperature, washed three times with PBS-T and developed using Supersignal West Pico Chemiluminescent substrate kit (Pierce Biotechnology, Inc., Rockford, IL, USA).

Statistical analysis. Statistical analysis was performed using SPSS 17.0 for Windows (SPSS, Inc., Chicago, IL, USA). The data were presented as percentages and compared using the $\chi^{2}$ test. $\mathrm{P}<0.05$ was considered to indicate a statistically significant difference.

\section{Results}

Immunohistochemical staining. Immunoreactivity for neuritin was located in the cytoplasm and nuclei of the cells, in which the cytoplasm was strongly stained as tan or brownish yellow, but the nucleus was weakly stained as light yellow or tan. Among the 58 gastric cancer tissues, 2 tissues did not express neuritin, 8 tissues exhibited neuritin expression and 48 tissues exhibited strong expression (Fig. 1). The expression rate of neuritin in the gastric cancer tissues was $96.55 \%$ and the strong expression rate was $82.76 \%$. By contrast, there were only 9 tissues with strong expression of neuritin in the 58 specimens of adjacent normal tissues (Fig. 2), which was significantly decreased compared with the strong expression rate in the gastric cancer tissues $(\mathrm{P}<0.05$; Table I). However, the overall expression rate of neuritin in the adjacent normal tissues (94.83\%) was not significantly different from the expression rate in the gastric cancer tissues $(\mathrm{P}>0.05$; Table II). Fig. 3 exhibits the staining of negative control tissue.

Neuritin mRNA expression. The mRNA expression of neuritin in gastric cancer tissues was also notably increased compared with the expression in the adjacent normal tissues, which was 
A

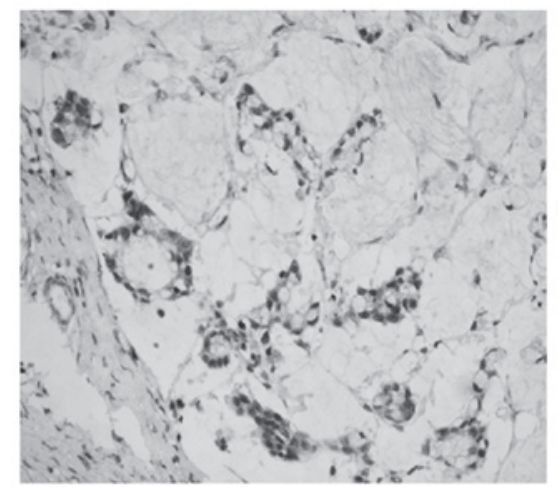

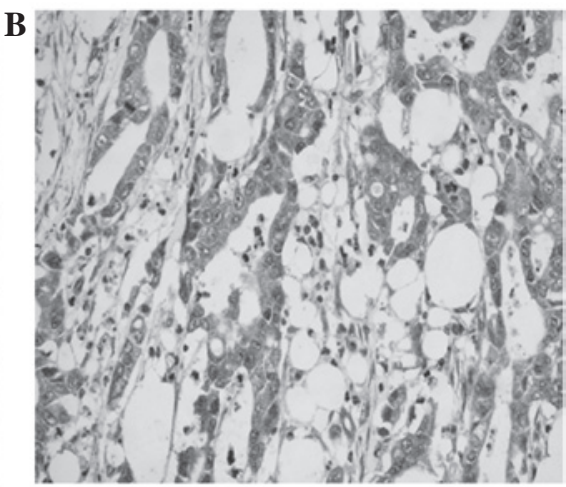

Figure 1. Representative images of neuritin expression in gastric cancer tissues in (A) patient 1 and (B) patient 2 (magnification, x200).

A

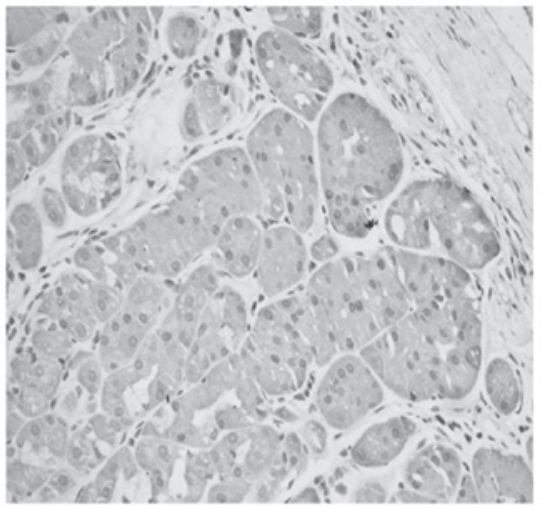

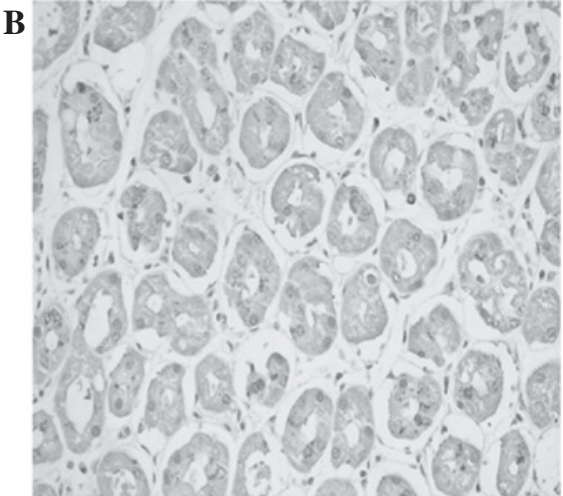

Figure 2. Representative images of neuritin expression in adjacent normal tissues in (A) patient 1 and (B) patient 2 (magnification, x200).

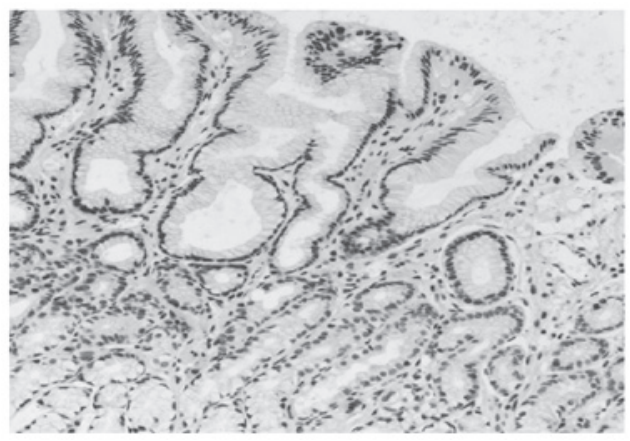

Figure 3. Represent image of negative control staining for neuritin, with no neuritin expression (magnification, $\mathrm{x} 200$ ).

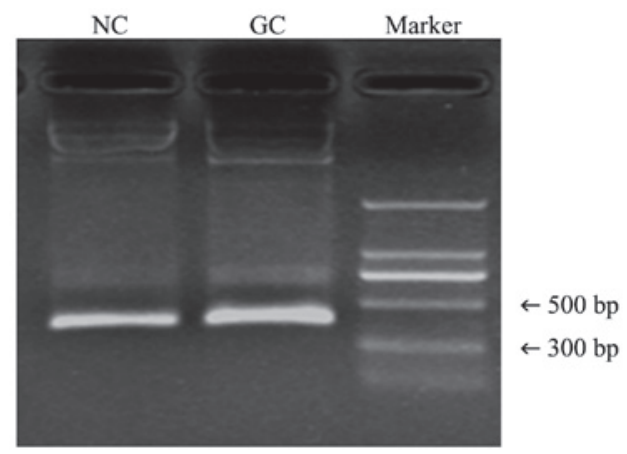

Figure 4. mRNA expression of neuritin in GC and adjacent NC tissues, as determined by reverse transcription-polymerase chain reaction. GC, gastric cancer; NC, normal control.

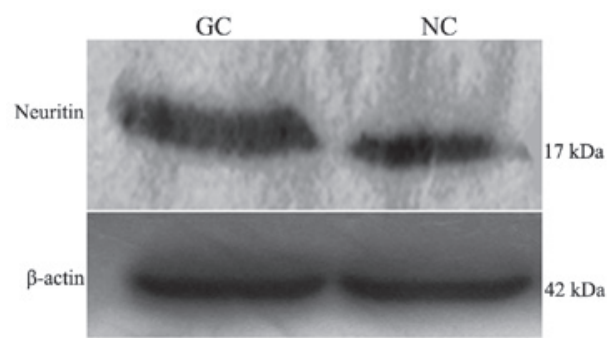

Figure 5. Expression of neuritin and $\beta$-actin in GC and adjacent NC tissues, as determined using western blot analysis. $\beta$-actin acted as an internal control. GC, gastric cancer; $\mathrm{NC}$, normal control.

consistent with the results for the expression of the neuritin protein (Fig. 4).

Western blot analysis. Total proteins extracted from the fresh frozen gastric cancer tissues and adjacent normal tissues were used to determine the expression of neuritin using western blot analysis. Gastric cancer tissues expressed an increased level of neuritin protein compared with adjacent normal tissues (Fig. 5).

Association between neuritin expression and the clinicopathological parameters of the patients. The overexpression of neuritin demonstrated no significant correlation with the gender or age of patients, tumor-node-metastasis (TNM) stage of the tumor, tumor depth, presence of lymph node metastasis, 
Table I. Strong expression of neuritin in gastric cancer and adjacent normal tissues $(n=58)$.

\begin{tabular}{lccr}
\hline Tissue type & $\begin{array}{c}\text { Strongly } \\
\text { expressed, }(\%)\end{array}$ & $\begin{array}{c}\text { Expressed and } \\
\text { not expressed, }(\%)\end{array}$ & $\chi^{2}$ \\
\hline Gastric cancer & $48(82.76)$ & $10(17.24)$ & 52.464 \\
Adjacent normal & $9(15.52)$ & $49(84.48)$ & $<0.05$ \\
\hline
\end{tabular}

Table II. Expression of neuritin in gastric cancer and adjacent normal tissues $(n=58)$.

\begin{tabular}{lccc}
\hline Tissue type & Expressed, n (\%) & Not expressed, n (\%) & $\chi^{2}$ \\
\hline Gastric cancer & $56(96.55)$ & $2(3.45)$ & 0 \\
Adjacent normal & $55(94.83)$ & $3(5.17)$ & $>0.05$ \\
\hline
\end{tabular}

Table III. Association between neuritin expression and the clinicopathological features of patients with gastric cancer.

\begin{tabular}{|c|c|c|c|c|c|}
\hline Parameters & Total, $\mathrm{n}$ & Expressed,n & Strongly expressed, $\mathrm{n}$ & $\chi^{2}$ & P-value \\
\hline \multicolumn{6}{|l|}{ Gender } \\
\hline Male & 39 & 6 & 33 & 0.000 & 1.000 \\
\hline Female & 17 & 2 & 15 & & \\
\hline \multicolumn{6}{|l|}{ Age, years } \\
\hline$<60$ & 22 & 2 & 20 & 0.253 & 0.615 \\
\hline$\geq 60$ & 34 & 6 & 28 & & \\
\hline \multicolumn{6}{|l|}{ Histological type } \\
\hline Well-differentiated & 1 & 0 & 1 & 0.669 & 1 \\
\hline Moderately-differentiated & 21 & 3 & 18 & & \\
\hline Poorly-differentiated & 34 & 5 & 29 & & \\
\hline \multicolumn{6}{|l|}{ TNM stage } \\
\hline 0 & 1 & 0 & 1 & 2.147 & 0.718 \\
\hline I & 15 & 1 & 14 & & \\
\hline II & 13 & 2 & 11 & & \\
\hline III & 25 & 5 & 20 & & \\
\hline IV & 2 & 0 & 2 & & \\
\hline \multicolumn{6}{|l|}{ Tumor depth } \\
\hline Tis & 1 & 0 & 1 & 4.456 & 0.343 \\
\hline $\mathrm{T} 1$ & 5 & 1 & 4 & & \\
\hline $\mathrm{T} 2$ & 20 & 1 & 19 & & \\
\hline $\mathrm{T} 3$ & 10 & 3 & 7 & & \\
\hline $\mathrm{T} 4$ & 20 & 3 & 17 & & \\
\hline \multicolumn{6}{|l|}{ Lymph node metastasis } \\
\hline N0, N1 & 31 & 2 & 29 & 2.195 & 0.138 \\
\hline $\mathrm{N} 2, \mathrm{~N} 3$ & 25 & 6 & 19 & & \\
\hline \multicolumn{6}{|l|}{ Distant metastasis } \\
\hline Positive & 2 & 0 & 2 & 0.000 & 1 \\
\hline Negative & 54 & 8 & 46 & & \\
\hline \multicolumn{6}{|l|}{ Pathological type } \\
\hline Protruding & 4 & 0 & 4 & 3.602 & 0.162 \\
\hline Ulcer & 44 & 5 & 39 & & \\
\hline Invasive & 8 & 3 & 5 & & \\
\hline
\end{tabular}


histological type, pathological type or the presence of distant metastasis ( $\mathrm{P}>0.05$; Table III).

\section{Discussion}

Neuritin is a small molecular substance that belongs to the neurotrophic factor family. Previous studies investigating neuritin have been focused on the nervous system, but more recent studies have revealed that certain tissues other than the nervous system may also express neuritin (5-21). Han et al (8) found that neuritin is expressed in human umbilical vein endothelial, liver and other normal human cells. Kojima et al (5) found that the heart, lungs and ovaries also expressed neuritin to a certain degree. Raggo et al injected 3T3 cells transfected with neuritin into nude mice and found that tumors developed at the transplanted sites (14). Le Jan et al (9) found that neuritin is overexpressed in lung cancer tissues, which may be involved in the development of lung cancer. However, neuritin is not found in bladder cancer cells or bile duct endothelial cancer cells (8). Cao et al found the overexpression of neuritin in breast cancer tissues is associated with lymph node metastasis and TNM staging of breast cancer (16). However, neuritin expression in gastric cancer, a common digestive system malignant tumor, has not been reported at present.

In the current study, neuritin was found to be expressed either in gastric cancer tissues or in adjacent normal tissues. Microscopic observation revealed that the majority of the adjacent normal tissues were moderately or weakly immunoreactive for neuritin and the immunostained cells accounted for $>50 \%$ of the cells in the sections, preliminarily indicating that the adjacent normal tissue to gastric cancer also expresses neuritin. However, the majority of gastric cancer cells were darkly stained as tan and these stained cells accounted for $>75 \%$ of the cells. Statistical analysis revealed that neuritin expression in gastric cancer tissues was significantly increased compared with the expression in the adjacent normal tissues $(\mathrm{P}<0.05)$, preliminarily indicating that neuritin was overexpressed in gastric cancer tissues. It has been reported that the overexpression of neuritin may partially inhibit the endocytosis of JAG1, a ligand in Notch signaling pathway, and thereby inhibit the activation of Notch signaling pathway. Certain studies have even found that the activation of Notch1 signaling pathways may inhibit the proliferation of gastric cancer cells (17). Therefore, to a certain extent, neuritin overexpression may promote the proliferation of gastric cancer cells by affecting the activation of the Notch signaling pathway, and thereby affecting the occurrence and development of gastric cancer, but this hypothesis remains to be confirmed. The present study suggested that the expression of neuritin was not correlated with the age of the patient, histological type or pathological type, which was consistent with the results found in breast cancer, reported by Cao et al (16). However, Cao et al also found that the expression of neuritin is associated with lymph node metastasis and TNM staging of breast cancer (16), which was not identified in the present study. This may result from the limited sample size. Thus, a larger sample size would be required in future studies.

In conclusion, neuritin expression demonstrates different expression between gastric cancer and adjacent normal tissues. The overexpression of neuritin provides a novel potential target for the prevention and treatment of gastric cancer.

\section{References}

1. Nedivi E, Hevroni D, Naot D, Israeli D and Citri Y: Numerous candidate plasticity-related gense revealed by differential cDNA cloning. Nature 363: 718-722, 1993.

2. Putz U, Harwell C and Nedivi E: Soluble CPG15 expressed during early development rescues cortical progenitor from apoptosis. Nat Neurosci 8: 323-331, 2005.

3. Cantallops I, Haas K and Cline HT: Postsynaptic CPG15 promotes synaptic maturation and presynaptic axon arbor elaboration in vivo. Nat Neurosci 3: 1004-1011, 2000.

4. Klussmann S and Martin-villalba A: Molecular targets in spinal cord injury. J Mol Med (Berl) 83: 657-671, 2005.

5. Kojima N, Shiojiri N, Sakai Y and Miyajima A: Expression of neuritin during liver maturation and regeneration. FEBS Lett 579: 4562-4566, 2005.

6. Seale P, Ishibashi J, Holterman C and Rudnicki MA: Muscle satellite cell-specific genes identified by genetic profiling of MyoD-deficient myogenic cell. Dev Biol 275: 287-300, 2004.

7. Gao R, Wang L, Sun J, Nie K, Jian H, Gao L, Liao X, Zhang H, Huang J and Gan S: MiR-204 promotes apoptosis in oxidative stress-induced rat Schwann cells by suppressing neuritin expression. FEBS Lett 588: 3225-3232, 2014.

8. Han D, Qin B, Liu G, Liu T, Ji G, Wu Y and Yu L: Characterization of neuritin as a novel angiogenic factor. Biochem Biophys Res Commun 415: 608-612, 2011.

9. Le Jan S, Le Meur N, Cazes A, Philippe J, Le Cunff M, Léger J, Corvol P and Germain S: Characterization of the expression of the hypoxia-induced genes neuritin, TXNIP and IGFBP3 in cancer. FEBS Lett 580: 3395-3400, 2006.

10. Tan YK and Fielding JW: Early diagnosis of early gastric cancer. Eur J Gastroenterol Hepatol 18: 821-829, 2006.

11. Zhang YC and Ou JM: Re-operation for postoperative recurrence of gastric cancer. Zhong Guo Shi Yong Wai Ke Za Zhi 22: 375-376, 2002 (In Chinese).

12. Li LX, Zhao YG, Zhang L and Fei Z: Study on the expression of neuritin in the tissues of human glioma. Zhong Hua Shen Jing Wai Ke Ji Bing Yan Jiu Za Zhi 8: 409-412, 2009 (In Chinese).

13. Zhang L, Zhao Y, Wang CG, Fei Z, Wang Y, Li L, Li L and Zhen HN: Neuritin expression and its relation with proliferation, apoptosis and angiogenesis in human astrocytoma. Med Oncol 28: 907-912, 2011.

14. Raggo C, Ruhl R, McAllister S, Koon H, Dezube BJ, Früh K and Moses AV: Novel cellular genes essential for transformation of endothelial cells by Kaposi's sarcoma-associated herpesvirus. Cancer Res 65: 5084-5095, 2005.

15. Yao JJ, Gao XF, Chow CW, Zhan XQ, Hu CL and Mei YA: Neuritin activates insulin receptor pathway to up-regulate Kv4.2-mediated transient outward $\mathrm{K}+$ current in rat cerebellar granule neurons. J Biol Chem 287: 41534-41545, 2012.

16. Cao J, Wang R and Hou J: Breast cancer tissues and its clinical significance neuritin of neurotrophic factors. J Jilin University (Medicine Edition) 39: 799-803, 2013.

17. Piazzi G, Bazzoli F and Ricciardiello L: Epigenetic silencing of Notch signaling in gastrointestinal cancers. Cell Cycle 11: 4323-4327, 2012.

18. Wang ZH, Li SJ, Qi Y, Zhao JJ, Liu XY, Han Y, Xu P and Chen XH: HuD regulates the cpg15 expressionvia the 3'-UTR and AU-rich element. Neurochem Res 36: 1027-1036, 2011.

19. Akten B, Kye MJ, Hao le T, Wertz MH, Singh S, Nie D, Huang J, Merianda TT, Twiss JL, Beattie CE, et al: Interaction of survival of motor neuron (SMN) and HuD proteins with mRNA cpg15 rescues motor neuron axonal deficits. Proc Natl Acad Sci USA 108: 10337-10342, 2011.

20. Sato H, Fukutani Y, Yamamoto Y, Tatara E, Takemoto M, Shimamura K and Yamamoto N: Thalamus-derived molecules promote survival and dendritic growth of developing cortical neurons. J Neurosci 32: 15388-153402, 2012.

21. Zito A, Cartelli D, Cappelletti G, Cariboni A, Andrews W, Parnavelas J, Poletti A and Galbiati M: Neuritin 1 promotes neuronal migration. Brain Struct Funct 219: 105-118, 2014. 